\title{
NEURO-FUZZY SYSTEM MODELLING FOR THE EFFECTS OF INTELLIGENT TRANSPORTATION ON ROAD ACCIDENT FATALITIES
}

\author{
Amir Masoud Rahimi
}

Original scientific paper

This paper proposes a Neuro-fuzzy system for quantitative assessment of the effects of intelligent transportation systems and technologies on road fatalities. The basic idea in developing Neuro-fuzzy system is the fact that intelligent transportation systems and technologies activate some safety mechanisms and in turn the activation of safety mechanisms will have a positive impact on road safety. Nine intelligent transportation systems are selected to study their effects on road safety. Expert questionnaire survey is performed and based on its results, a fuzzy inference system is developed to estimate the fatality rate in a given transportation system. Adaptive network based fuzzy inference system (ANFIS) method is used to identify the FIS properties including fuzzy rule base and FIS output functions. The result of neuro-fuzzy modelling shows that camera monitoring and drowsiness monitoring/warning are the most influencing technologies in avoiding road accidents and fatalities.

Keywords: ANFIS; intelligent transportation systems; road accident; safety

Modeliranje neuro-fuzzy sustava u svrhu analize učinaka inteligentnog prijevoza na broj žrtava kod prometnih nezgoda

Izvorni znanstveni članak

U radu se predlaže neuro-fuzzy sustav za kvantitativnu procjenu učinaka inteligentnog prijevoznog sustava i tehnologija na broj žrtava. Osnovna ideja razvoja neuro-fuzzy sustava zasniva se na činjenici da inteligentni prijevozni sustavi i tehnologije aktiviraju neke sigurnosne mehanizme, a aktiviranje sigurnosnih mehanizama djelovat će pozitivno na sigurnost na cesti. Odabrano je devet inteligentnih prijevoznih sustava u svrhu proučavanja njihovih učinaka na sigurnost na cesti. Provedena je stručna anketa i na osnovu rezultata razvijen je sustav neizrazitog zaključivanja kako bi se procijenila stopa smrtnosti postojećeg prijevoznog sustava. Metoda prilagodljivog sustava neuro-neizrazitog zaključivanja (ANFIS) primijenjena je za identifikaciju svojstava sustava neizrazitog zaključivanja - FIS-a uključujući bazu fuzzy pravila i izlazne funkcije FIS-a. Rezultat neuro-fuzzy modeliranja pokazuje da su nadzor kamerom i nadzor/upozorenje pospanosti najučinkovitije tehnologije za sprečavanje prometnih nezgoda.

Ključne riječi: ANFIS; inteligentni prijevozni sustavi; prometna nezgoda; sigurnost

\section{Introduction}

Safe transportation of goods and passengers is the primary objective of every transportation system. However, fatalities are always there and in the quest to create safe systems, practitioners believe human factors in both physical and behavioural aspects are the key to manage safety.

The main problem in transportation safety is the human, or driver and three different approaches have been suggested to tackle this problem: i) to avoid exposure to road risk, here road transportation can be replaced by other alternative transportation modes such as train, marine, and air transportation, ii) to reduce the probability of an accident. Here the focus is on reducing human error by training and human factors engineering, iii) to minimize the unwanted consequences of an accident. Here the focus is on the measures that could be taken post-accident to minimize injuries or fatalities after an accident occurs.

Efforts to minimize human error in road transportation have led to development of intelligent transportation systems (ITS) that could replace or support human brain to take action or make decisions. Some examples are intelligent brakes, speed control, information systems, intelligent monitoring systems, accident detection technologies, intelligent training systems.

In intelligent transportation network, intelligent technologies and systems are placed to help human in better decision making and actions. Therefore, to manage intelligent transportation it is crucial to have a reliable estimate of the effects that intelligent systems could have on the road safety performance. This paper proposes a fuzzy inference system for quantitative assessment of the effects of ITS on road fatalities. In the literature, ITS has their effects on safety performance via activation of some safety mechanisms. The unique feature of this study is that these mechanisms are used to develop a fuzzy rule base which is the heart of fuzzy inference system. Furthermore, the proposed fuzzy inference system has two unique features in the modelling which are modelling fuzzy uncertainty and modelling complex relationship between application of ITS and road safety.

Intelligent systems in transportation can be categorized in two different groups: intelligent systems in infrastructures (such as Automatic Enforcement System, road control systems) and intelligent systems in vehicles (Emergency braking, speed limit alert, alcohol test, safety belt reminder) $[1,2]$.

In the literature, to assess the effects of intelligent technologies on road safety performance, researchers refer to some safety mechanisms which, if activated, could have positive improving effect on road safety. Kulmala [2] numbered 9 safety mechanisms that if activated could improve safety and studied safety effect of 12 intelligent technologies.

Road safety performance has been the subject of many research works. Kulmala [2] emphasized the need for a comprehensive framework in which different safety aspects including exposure rate, accident risk, and unwanted outcome management had been taken into consideration. Gitelman et al. [3] studied four groups of different safety indicators and suggested that all these indicator groups should be weighted into a single indicator. These groups include policy indicators, final 
outcome indicators such as fatalities, middle output indicators such as behaviour modification, technology utilization, and finally infrastructure indicators such as number of vehicles, congestion and traffic management. Yannis et al. [4] studied behavioural indicators (safety belt utilization, avoidance of alcohol and drug usage) along with vehicle indicators (vehicle reliability, air bag) and discussed the need for other safety indicators including policy, infrastructure, management and intelligent technologies (see also Christoph et al. [5] for more vehicle related indicators). Gitelman et al. [6] focused on safety indicators in managing post-accident unwanted consequences. They introduced five groups of safety indicators including emergency service accessibility, emergency personnel accessibility, emergency facilities accessibility, response time to emergency calls, and hospital bed accessibility for accident injuries. Ma et al. [7] categorized road safety indicators according to the geographical areas including regional, urban, and highway. Tingvall et al. [8] studied the relationship between middle output indicators and final safety indicators and using a regression model they showed the significance of relationship between middle output indicators such as behaviour modification and technology utilization, and fatality rate.

Modelling the effects of ITS on road safety requires a comprehensive framework with the following unique features [2] to include exposure, accident risk, and postaccident outcome prevention, ii) to include both technology and human behaviour. Vanderschuren [9] investigated the effect of three ITS technologies on road safety in South Africa. He concluded that ITS has significant effects on safety, transportation speed, efficiency, costs, energy consumption, environment and customer satisfaction. Other studies reported on improving effects of intelligent transportation in manufacturing plants [10], supply chain [11]. Touran et al. [12] in a simulation study investigated the role of intelligent cruise control system in preventing collisions and injuries. Lai et al. [13] studied the safety effects of intelligent speed control system. They discussed the direct effects of this ITS along with its indirect effects on driver behaviour. They showed that intelligent speed control system could reduce road accidents by 33 percent. In a time period of 60 years, this intelligent system could save up to 7 times of its costs.

Despite the proven advantages of ITSs, some researchers discussed the negative effects these technologies could have on road safety [14]. Vashitz et al. [15] reported on the mental load and distractions that embedded traffic information systems could bring about [15]. Another line of research regarding the effectiveness of ITS systems is focused on multivariate analysis of the ITS projects $[16,17]$. In these studies, safety effects of ITS systems are studied along with their socio-economic effects.

According to the literature reviewed above, two aspects of modelling the effects of ITSs have received less attention namely complexity and uncertainty. Complexity in estimating the effects of ITSs arises from existence of many influencing variables in the modelling environment including human, technology, and road. Furthermore, all decision making in transportation system involves human cognition, preferences, characteristics, and decision styles and all these features are well-known sources of uncertainty. Therefore, any effort to study the effect of ITS technologies on road safety should address both complexity and uncertainty in modelling environment. Here this study proposes the use of fuzzy inference systems to address both complexity and uncertainty. Complexity is handled by incorporation of a number of fuzzy rules associated with safety mechanisms and uncertainty is handled by associating different fuzzy values to the system variables. The remaining sections of current paper are structured as follows: Section 2 describes intelligent transportation systems briefly; Section 3 explains transportation safety mechanisms; Section 4 describes the proposed methodology; in Section 5 , results are presented; and finally, Section 6 concludes our work.

\section{Intelligent transportation systems}

In the current study we have chosen 9 intelligent transportation systems to study their effects on road safety. The following list includes four system-based ITS and five vehicle-based ITS. The first four ITSs are system-based and the rest are vehicle-based.

- Speed control in highways

- Camera monitoring

- Red light running camera control

- Real-time traffic information system

- Full-speed range adapt, cruise control

- Lane keeping support

- $\quad$ Speed alert

- Emergency call e-Call

- Drowsiness monitoring/warning.

More details about these systems can be found in eSafety [18]. Because our research method is based on a questionnaire survey, we have chosen those intelligent technologies that our target respondents are very familiar with and have experience in using those technologies. The technologies in this list are more common in developing countries, for example in Iran, and it is more probable for respondents to have a good sense of their effects on road safety. Moreover respondents might gain knowledge of these technologies from other people's experience and reviews.

\section{Transportation safety mechanisms}

With reference to the work performed by Kulmala [2], the safety mechanisms in road safety are:

- Direct in-vehicle modification of the driving task.

- Direct influence by roadside systems.

- Indirect modification of user behaviour.

- Indirect modification of non-user behaviour.

- Modification of interaction between road users.

- Modification of exposure.

- Modification of modal choice.

- Modification of route choice.

- Modification of accident consequences only.

The list is based on the ten-point list proposed by Draskóczy et al. [19]. After consulting with a board of 
experts, we have shortened this list to a four-bullet general list:

- Modification of user behaviour - by giving information, advice, and assistance or taking over part of the task. This may influence driver attention, mental load, adapt to the changing situation, and decision on action.

- Modification of exposure - This mechanism covers changes in the amount of travelling, i.e. whether the road user decides to make less, or shorter trips. This can be achieved by giving information, recommendation, restrictions, debiting. This is an important mechanism for the safety effects as changes in exposure affect the expected number of all crashes, injuries and fatalities.

- Modification of modal choice - Different travel modes have different accident risks, therefore any measure which influences modal choice, has also impact on traffic safety. Public transport, tram, metro, and bus are different in the rate of accidents.

- Modification of accident consequences - This modification can be achieved by intelligent injury reducing systems in the vehicle, by quick and accurate crash reporting and call for rescue, by reduced rescue time for example in-vehicle emergency call system, i.e. eCall.

\section{Neuro-fuzzy system development}

The basic idea in developing Neuro-fuzzy system is the fact that intelligent transportation systems and technologies activate some safety mechanisms and in turn the activation of safety mechanism will have a positive impact on road safety or fatality rate. Therefore in such cause and effect setting, three layers can be differentiated. The first layer corresponds to the ITS technologies. The second layer corresponds with safety mechanisms and the third layer represents safety output indicators i.e. fatality rate. These layers in the road safety system could correspond to three layers in a fuzzy inference system (FIS). The first layer activates safety mechanisms therefore it could be considered as input layer in FIS. The second layer contains safety mechanisms which could be used to develop a fuzzy rule base for FIS. The last layer is the output of road safety system and can be treated as FIS output layer (see Fig. 1).

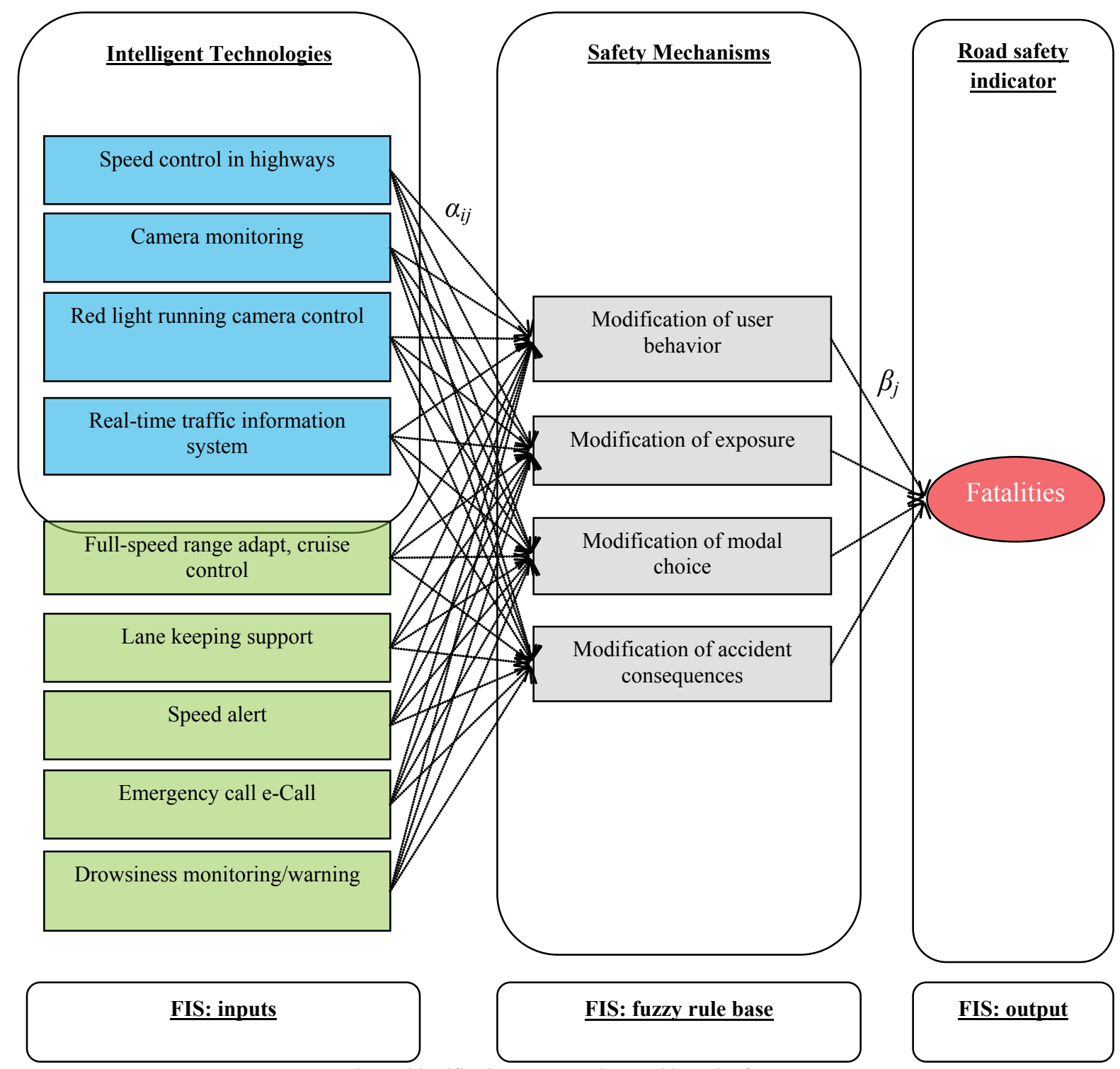

Figure 1 FIS layers identification correspondence with road safety system 
For quantification of the relationships between different layers in FIS, we need to estimate two groups of unknown variables: the degree by which safety mechanism $\mathrm{j}$ is activated by ITS technology $\mathrm{i}\left(\alpha_{i j}\right)$, and the impact of the activated safety mechanism $\mathrm{j}$ on road fatality rate $\left(\beta_{j}\right)$. For estimation of $\alpha_{i j}$ and $\beta_{j}$, a questionnaire survey has been performed. The respondents are a group of road safety experts who are well knowledgeable and experienced in the application of ITS technologies including academics, practitioners, and auto industry experts. An expert questionnaire was designed to collect expert opinion about the effects in road safety system. The respondents are asked to express their estimation about $\alpha \mathrm{ij}$ and $\beta \mathrm{j}$ with a number in a five- point Likert scale from 1 to 5 representing very small effect, small effect, moderate effect, relatively big effect, and strong positive effect. A group of 36 experts was targeted and the questionnaires were distributed between them. With a respond rate of $89 \%, 32$ completed responds were collected and the averages of the estimation results are presented in Tabs. 1 and 2. In Tab. 2 the results are normalized so as their summation equals unity. The reliability and repeatability of the questionnaire results has been tested. We used retest-test proposed by Chadwick [20] and calculated Intra-class Correlation Coefficient (ICC) using SPSS 15 software. The results approved reliability and repeatability of the questionnaire results.

Table 1 Expert estimation of the effect of ITS technologies on safety mechanisms $\left(\alpha_{i j}\right)$

\begin{tabular}{|c|c|c|c|c|}
\hline \multirow{2}{*}{ ITS } & \multicolumn{4}{|c|}{ Safety mechanisms } \\
\hline & Mechanism 1 & Mechanism 2 & Mechanism 3 & Mechanism 4 \\
\hline Speed control in highways & 4,18 & 4,01 & 1,26 & 1,71 \\
\hline Camera monitoring & 4,00 & 3,85 & 2,79 & 3,09 \\
\hline Red light running camera control & 4,09 & 1,28 & 1,36 & 1,08 \\
\hline Real-time traffic information system & 2,09 & 2,17 & 4,85 & 2,98 \\
\hline Full-speed range adapt, cruise control & 4,64 & 3,97 & 1,23 & 1,01 \\
\hline Lane keeping support & 2,83 & 4,22 & 1,61 & 1,06 \\
\hline Speed alert & 3,98 & 3,66 & 1,53 & 1,08 \\
\hline Emergency call e-Call & 1,26 & 1,02 & 1,23 & 4,56 \\
\hline Drowsiness monitoring/warning & 4,35 & 4,01 & 1,12 & 2,25 \\
\hline
\end{tabular}

Table 2 Expert estimation of the effect of safety mechanisms on road fatality rate $\left(\beta_{j}\right)$

\begin{tabular}{|c|c|c|c|c|}
\hline & \multicolumn{4}{|c|}{ Safety mechanisms } \\
\cline { 2 - 5 } & $\begin{array}{c}\text { Mechanism } \\
1\end{array}$ & $\begin{array}{c}\text { Mechanism } \\
2\end{array}$ & $\begin{array}{c}\text { Mechanism } \\
3\end{array}$ & $\begin{array}{c}\text { Mechanism } \\
4\end{array}$ \\
\hline $\begin{array}{c}\text { Effect on } \\
\text { fatality rate }\end{array}$ & 0,3 & 0,3 & 0,15 & 0,25 \\
\hline
\end{tabular}

One crucial step in developing a FIS is the fuzzification of its inputs. In this study we propose to use a finite discourse of $[1,10]$ for quantification of inputs. Number one shows the absence of ITS in the transportation system. It means that ITS technology is not used in the system. On the other hand, number 10 shows the state-of-the-art level of sophistication about an ITS in the transportation system. Uncertainty about the level of ITS implementation is represented by fuzzy sets where for each of ITS (or FIS inputs), four fuzzy sets with Gaussian membership functions are considered (Fig. 2). In Fig. 2, cluster 1 represents the lowest level of sophistication of ITS in the system and cluster 4 represents the highest level of sophistication of ITS. For cluster 1, the center (mean value) is 1 and the variance is $\sigma^{2}=3,5$. It should be noted that all clusters have the same variance $\sigma^{2}=3,5$.

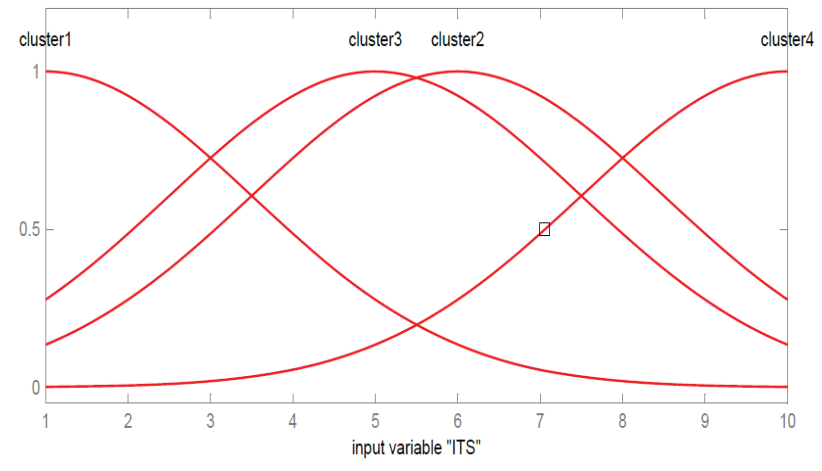

Figure 2 Fuzzification of the first FIS input (ITS1)

Similarly, all other ITS (FIS inputs) are fuzzified with the use of Gaussian membership functions. The variances of all clusters are the same and clusters are only different in their centers. Tab. 3 represents cluster centers for the fuzzification of FIS inputs.

Table 3 Cluster centers for the fuzzification of FIS inputs

\begin{tabular}{|c|c|c|c|c|}
\hline \multirow[t]{2}{*}{ ITS (FIS inputs) } & \multicolumn{4}{|c|}{ Cluster centers } \\
\hline & Cluster 1 & Cluster 2 & Cluster 3 & Cluster 4 \\
\hline Speed control in highways (in1) & 4 & 2 & 10 & 2 \\
\hline Camera monitoring (in2) & 5 & 7 & 7 & 1 \\
\hline Red light running camera control (in3) & 6 & 3 & 7 & 5 \\
\hline Real-time traffic information system (in4) & 4 & 3 & 8 & 8 \\
\hline Full-speed range adapt, cruise control (in5) & 7 & 4 & 8 & 5 \\
\hline Lane keeping support (in6) & 2 & 6 & 5 & 10 \\
\hline Speed alert (in7) & 8 & 6 & 6 & 1 \\
\hline Emergency call e-Call (in8) & 8 & 2 & 4 & 9 \\
\hline Drowsiness monitoring/warning (in9) & 5 & 3 & 6 & 5 \\
\hline
\end{tabular}


Now, based on the estimated values in Tabs. 1 and 2 and with the use of fuzzy variables represented by the clusters in Tab. 3, we can develop a fuzzy inference system to estimate the fatality rate in a given transportation system. We have used the adaptive network based fuzzy inference system (ANFIS) method developed by Jang et al. [21] to identify the FIS properties including fuzzy rule base and FIS output functions (here fatality rate). A specific approach in neuro-fuzzy development is the adaptive neuro-fuzzy inference system (ANFIS), which has shown significant results in modelling nonlinear functions [22]. ANFIS uses a feed forward network to search for fuzzy decision rules that perform well on a given task. Using a given input-output data set, ANFIS creates a FIS whose membership function parameters are adjusted using a back-propagation algorithm alone or a combination of a back-propagation algorithm with a least squares method. This allows the fuzzy systems to learn from the data being modelled. For more details the interested readers are referred to Jang et al. [21].

\section{Results}

The first result of ANFIS training is a fuzzy rule base for quantification of fatality rate index based on the evaluations of the ITS technologies employed in the transportation system. The resulting fuzzy rule is as follows:
- Rule 1. If (ITS1 is in1cluster1) and (ITS2 is in2cluster1) and (ITS3 is in3cluster1) and (ITS4 is in4cluster1) and (ITS5 is in5cluster1) and (ITS6 is in6cluster1) and (ITS7 is in7cluster1) and (ITS8 is in8cluster1) and (ITS9 is in9cluster1) then (FatalityRateIndex is $\mathrm{fl}$ )

- Rule 2. If (ITS1 is in1cluster2) and (ITS2 is in2cluster2) and (ITS3 is in3cluster2) and (ITS4 is in4cluster2) and (ITS5 is in5cluster2) and (ITS6 is in6cluster2) and (ITS7 is in7cluster2) and (ITS8 is in8cluster2) and (ITS9 is in9cluster2) then (FatalityRateIndex is f2)

- Rule 3. If (ITS1 is in1cluster3) and (ITS2 is in2cluster3) and (ITS3 is in3cluster3) and (ITS4 is in4cluster3) and (ITS5 is in5cluster3) and (ITS6 is in6cluster3) and (ITS7 is in7cluster3) and (ITS8 is in8cluster3) and (ITS9 is in9cluster3) then (FatalityRateIndex is f3)

- Rule 4. If (ITS1 is in1cluster4) and (ITS2 is in2cluster4) and (ITS3 is in3cluster4) and (ITS4 is in4cluster4) and (ITS5 is in5cluster4) and (ITS6 is in6cluster4) and (ITS7 is in7cluster4) and (ITS8 is in8cluster4) and (ITS9 is in9cluster4) then (FatalityRateIndex is f4)

In this fuzzy rule base the input clusters were identified before as in Tab. 3. Moreover, the output functions of $\mathrm{fl}, \mathrm{f} 2, \mathrm{f} 3$, and $\mathrm{f} 4$ in the THEN part of each rule are linear functions whose coefficients are presented in Tab. 4.

Table 4 The coefficients of ITS technologies in the fuzzy rules

\begin{tabular}{|c|c|c|c|c|c|c|c|c|c|}
\hline Output Function & ITS1 & ITS2 & ITS3 & ITS4 & ITS5 & ITS6 & ITS7 & ITS8 & ITS9 \\
\hline rule 1: f1 & 3,1 & 3,5 & 2,1 & 2,8 & 3,0 & 2,6 & 2,8 & 2,0 & 3,2 \\
\hline rule 2: f2 & 3,1 & 3,5 & 2,1 & 2,8 & 3,0 & 2,6 & 2,8 & 2,0 & 3,2 \\
\hline rule 3: f3 & 3,1 & 3,5 & 2,1 & 2,8 & 3,0 & 2,6 & 2,8 & 2,0 & 3,2 \\
\hline rule 4: f4 & 3,1 & 3,5 & 2,1 & 2,8 & 3,0 & 2,6 & 2,8 & 2,0 & 3,2 \\
\hline
\end{tabular}

As it can be seen in Tab. 4, the coefficients of each of ITS technologies in the output of all the fuzzy rules are almost the same and this means that this entire fuzzy rule could be summarized into a final formulation for road safety indicator:
Fatality rate index

$=3,1 \times \operatorname{ITS} 1+3,5 \times \mathrm{ITS} 2+2,1 \times \operatorname{ITS} 3+2,8 \times \operatorname{ITS} 4+$

$3,0 \times \operatorname{ITS} 5+2,6 \times \operatorname{ITS} 6+2,8 \times \operatorname{ITS} 7+2,0 \times \operatorname{ITS} 8+3,2 \times \operatorname{ITS} 9$

Table 5 Fatality rate index for 13 sample systems

\begin{tabular}{|c|c|c|c|c|c|c|c|c|c|c|c|}
\hline & ITS1 & ITS2 & ITS3 & ITS4 & ITS5 & ITS6 & ITS7 & ITS8 & ITS9 & Questionnaire fatality rate & FIS Estimated fatality rate \\
\hline System 1 & 1 & 1 & 9 & 6 & 4 & 5 & 7 & 3 & 6 & 107 & 112,1 \\
\hline System 2 & 3 & 2 & 4 & 9 & 3 & 2 & 5 & 4 & 8 & 112 & 11,6 \\
\hline System 3 & 7 & 7 & 9 & 7 & 4 & 4 & 2 & 7 & 8 & 147 & 152,5 \\
\hline System 4 & 3 & 2 & 3 & 5 & 3 & 10 & 7 & 7 & 10 & 136 & 137,6 \\
\hline System 5 & 9 & 5 & 6 & 7 & 9 & 6 & 2 & 5 & 6 & 118 & 15,1 \\
\hline System 6 & 10 & 1 & 2 & 6 & 1 & 1 & 8 & 8 & 7 & 144 & 151,7 \\
\hline System 7 & 7 & 3 & 10 & 5 & 4 & 10 & 6 & 5 & 6 & 152 & 14,3 \\
\hline System 8 & 7 & 6 & 8 & 8 & 7 & 1 & 10 & 5 & 1 & 123 & 123,4 \\
\hline System 9 & 3 & 5 & 8 & 3 & 2 & 6 & 7 & 7 & 5 & 121 & 126,9 \\
\hline System 10 & 7 & 4 & 8 & 1 & 1 & 9 & 4 & 4 & 8 & 125 & 124,2 \\
\hline System 11 & 1 & 9 & 7 & 4 & 3 & 3 & 5 & 5 & 7 & 186 & 17,5 \\
\hline System 12 & 9 & 10 & 4 & 9 & 3 & 8 & 10 & 10 & 1 & 149 & 145,1 \\
\hline System 13 & 7 & 5 & 9 & 7 & 5 & 10 & 1 & 7 & 3 & & \\
\hline
\end{tabular}

For verification of fatality rate index formula, we conduct a comparison test between the actual fatality rate index derived from questionnaire survey and the estimated fatality rate from the final formula. The fatality rate index is calculated for 13 sample systems (Tab. 5).
Fig. 3 depicts the questionnaire-based fatality rate and the estimated FIS-based fatality rate. As seen, the change in actual fatality rate is well tracked by the FIS-based formula. 
The difference between questionnaire fatality rate and FIS estimated fatality rate is the basis for comparison. For a more formal comparison, we propose to calculate mean absolute percentage error (MAPE) to evaluate the difference, as follows:

$$
M A P E=100 \times \frac{\sum_{k=1}^{13}\left|\frac{Q F R_{k}-F I S F R_{k}}{Q F R_{k}}\right|}{13},
$$

where $Q F R$ is fatality rate from questionnaire and FISFR is the estimated fatality rate from the developed FIS formula. The calculation shows that $M A P E=2,7 \%$ indicating a relatively low error rate therefore the formula (1) can be verified as an accurate model to evaluate the effects of ITS technologies on fatality rate index in a given transportation system.

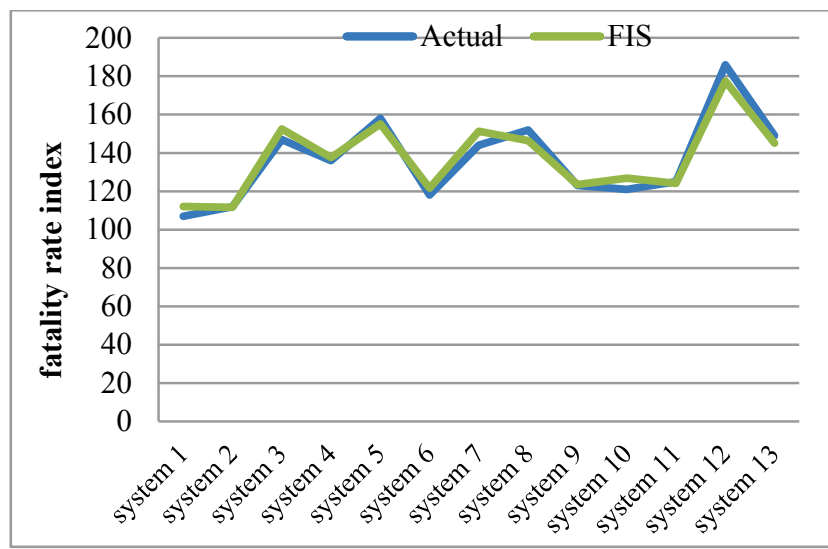

Figure 3 Comparison between actual and FIS estimated fatality rate

According to the final formula for fatality rate index, the coefficients of ITS technologies can be served as a degree of impact each ITS technology could have on road transport safety. Therefore, based upon these degrees of impact, a ranking can be developed between ITS technologies with respect to the influence in road safety system (Tab. 6). The ranking result shows that camera monitoring is the most influencing technology in avoiding road accidents and fatalities. This is because camera monitoring is very influential in both accident prevention and post-accident rescue operation. The second technology that could have a huge impact on road safety is determined to be drowsiness monitoring/warning. According to the official road accident investigation reports, many accidents happen because of drowsy drivers in inter-city journeys. The third impact rank belongs to Speed control in highways. Again speed is another major cause in Iran road accidents and this technology can be very influential in preventing injurious accidents. On the other hand, Emergency call e-Call is determined to be the least influential technology. This may be because of the crowd and busy highways and roads that whenever an accident occurs, there will be people who could immediately inform emergency by their cell-phones hence no need for e-call. Despite the low rank of e-call, expert respondents believe that this technology can be very useful in some cases. But in comparison with other technologies, it is less useful especially in developing countries where communication network and infrastructures suffer from uncertainty in every-time availability.

Table 6 ITS technologies and their impact ranking on road safety indicator

\begin{tabular}{|c|c|c|}
\hline \\
\hline \multirow{2}{*}{ ITS } & \multicolumn{2}{|c|}{ Impact on safety } \\
\hline & Coefficient & Rank \\
\hline Speed control in highways & 3,1 & 3 \\
\hline Camera monitoring & 3,5 & 1 \\
\hline Red light running camera control & 2,1 & 8 \\
\hline $\begin{array}{l}\text { Real-time traffic information } \\
\text { system }\end{array}$ & 2,8 & 5 \\
\hline $\begin{array}{l}\text { Full-speed range adapt, cruise } \\
\text { control }\end{array}$ & 3 & 4 \\
\hline Lane keeping support & 2,6 & 7 \\
\hline Speed alert & 2,8 & 5 \\
\hline Emergency call e-Call & 2 & 9 \\
\hline Drowsiness monitoring/warning & 3,2 & 2 \\
\hline
\end{tabular}

\section{Conclusions}

This paper proposed a Neuro-fuzzy system for quantitative assessment of the effects of ITS on road fatalities. The basic idea in developing Neuro-fuzzy system was the fact that intelligent transportation systems and technologies activate some safety mechanisms and in turn the activation of safety mechanism will have a positive impact on road safety or fatality rate. ITS technologies affect safety performance via activation of four safety mechanisms: Modification of user behaviour, Modification of exposure, Modification of modal choice, and Modification of accident consequences. The unique feature of this study is that these mechanisms are used to develop a fuzzy inference system with two unique features: modelling fuzzy uncertainty and modelling complex relationship between application of ITS and road safety. Complexity is handled by incorporation of a number of fuzzy rules associated with safety mechanism and uncertainty is handled by associating different fuzzy values to the system variables. Nine intelligent transportation systems were selected to study their effects on road safety. The technologies in the list were more common in Iran as a developing country hence it was more probable for respondents to have a good sense of their effects on road safety. Expert questionnaire survey was performed and based on its results, a fuzzy inference system was developed to estimate the fatality rate in a given transportation system. Adaptive network based fuzzy inference system (ANFIS) method was used to identify the FIS properties including fuzzy rule base and FIS output functions. The result of ANFIS training was a fuzzy rule base for quantification of fatality rate index based on the evaluations of the ITS technologies employed in the transportation system. The entire fuzzy rule was summarized into a verified formulation for road safety indicator. The result of neuro-fuzzy modelling showed that camera monitoring and drowsiness monitoring/warning could be the most influencing technologies in avoiding road accidents and fatalities.

This could be served as a basis for ITS system development strategy for those agencies responsible for safety management planning and control. Future research could be directed into two main lines. First, the approach of this study could be applied for impact assessment of 
other ITS technologies which were not considered in this paper. Second, the interaction effect of ITS technologies with other road safety management factors such as training, police enforcement, vehicle safety and road quality may be of interest. Future research could address this problem by development of the proposed approach so that the effects of other factors and their ITS interaction effect are also analyzed. Moreover, the safety impact of ITS technologies may be much dependent on the cultural factors of road users including drivers and pedestrians. Here, special attention should be paid to traffic safety culture factors such as attitudes and values of road users.

\section{References}

[1] eSafetySupport,. // eSafety Interactive Car. http://www.esafetysupport.org/download/interactive car/light.html. 2009.

[2] Kulmala, R. Ex-ante assessment of the safety effects of intelligent transport systems, // Accident Analysis \& Prevention, 42, 4 (2010), pp. 1359-1369. https://doi.org/10.1016/j.aap.2010.03.001

[3] Gitelman, V.; Doveh, E.; Hakkert, S. Designing a composite indicator for road safety. // Safety Science. 48, 9(2010), pp. 1212-1224. https://doi.org/10.1016/j.ssci.2010.01.011

[4] Yannis G.; Weijermars, W.; Gitelman, V.; Vis, M.; Chaziris, A.; Papadimitriou, E.; Lima Azevedo, C. Road safety performance indicators for the interurban road network. // Accident Analysis \& Prevention. 60, 1(2013), pp. 384-395. https://doi.org/10.1016/j.aap.2012.11.012

[5] Christoph, M.; Vis, M. A.; Rackliff, L.; Stipdonk, H. A road safety performance indicator for vehicle fleet compatibility. // Accident Analysis \& Prevention. 60 (2013), pp. 396-401. https://doi.org/10.1016/j.aap.2013.07.018

[6] Gitelman, V.; Auerbach, K.; Doveh, E. Development of road safety performance indicators for trauma management in Europe. // Accident Analysis \& Prevention. 60(2013), pp. 412-423. https://doi.org/10.1016/j.aap.2012.08.006

[7] Ma, Z.; Shao, Chunfu; Ma, Sheqiang; Ye, Zeng. Constructing road safety performance indicators using Fuzzy Delphi Method and Grey Delphi Method. // Expert Systems with Applications. 38, 3(2011), pp. 1509-1514. https://doi.org/10.1016/j.eswa.2010.07.062

[8] Tingvall, C.; Stigson, H.; Eriksson, L.; Johansson, R.; Krafft, M.; Lie, A. The properties of Safety Performance Indicators in target setting, projections and safety design of the road transport system. // Accident Analysis \& Prevention. 42, 2(2010), pp. 372-376 https://doi.org/10.1016/j.aap.2009.08.015

[9] Vanderschuren, M. Safety improvements through Intelligent Transport Systems: A South African case study based on microscopic simulation modelling. // Accident Analysis \& Prevention. 40, 2(2008), pp. 807-817. https://doi.org/10.1016/j.aap.2007.09.025

[10] Horberry, T.; Larsson, T. J.; Johnston, I.; Lambert, J. Forklift safety, traffic engineering and intelligent transport systems: a case study. // Applied Ergonomics. 35, 6(2004), pp. 575-581. https://doi.org/10.1016/j.apergo.2004.05.004

[11] Mondragon, A. E.; Lalwani, C.; Coronado Mondragon, E. S.; Pawar, K. Intelligent transport systems in multimodal logistics: A case of role and contribution through wireless vehicular networks in a sea port location. // International Journal of Production Economics. 137, 1(2012), pp. 165175. https://doi.org/10.1016/j.jpe.2011.11.006

[12] Touran, A.; Brackstone, M. A.; McDonald, M. A collision model for safety evaluation of autonomous intelligent cruise control. // Accident Analysis \& Prevention. 31, 5(1999), pp. 567-578.

https://doi.org/10.1016/S0001-4575(99)00013-5

[13] Lai, F.; Carsten, O.; Tate, F. How much benefit does Intelligent Speed Adaptation deliver: An analysis of its potential contribution to safety and environment. // Accident Analysis \& Prevention. 48, (2012), pp. 63-72. https://doi.org/10.1016/j.aap.2011.04.011

[14] Jagtman, H. M.; Hale, A. R.; Heijerm, T. Ex ante assessment of safety issues of new technologies in transport. // Transportation Research Part A: Policy and Practice. 40, 6(2006), pp. 459-474. https://doi.org/10.1016/j.tra.2005.08.007

[15] Vashitz, G.; Shinar, D.; Blum, Y. In-vehicle information systems to improve traffic safety in road tunnels. // Transportation Research Part F: Traffic Psychology and Behaviour. 11, 1(2008), pp. 61-74. https://doi.org/10.1016/j.trf.2007.07.001

[16] Marell, A.; Westin, K. Intelligent transportation system and traffic safety-drivers perception and acceptance of electronic speed checkers. // Transportation Research Part C: Emerging Technologies. 7, 2-3(1999), pp. 131-147. https://doi.org/10.1016/s0968-090x(99)00016-9

[17] Juan Z.; Wu, J.; McDonald, M. Socio-Economic Impact Assessment of Intelligent Transport Systems. // Tsinghua Science \& Technology. 11, 3(2006), pp. 339-350. https://doi.org/10.1016/S1007-0214(06)70198-5

[18] eSafety. // eSafety Effects Database. Retrieved October, 2015 from: http://www.esafety-effects-database.org/ applications.html

[19] Draskóczy, M.; Carsten, O.; Kulmala, R. Road safety guidelines, Co-ordinated Dissemination in Europe of Transport Telematics, Telematics Application Programme: Transport Sector. Deliverable to European Commission DG X111. 1998

[20] Chadwick, B. A.; Bahr, H. M.; Albrecht, S. L. Social science research methods, Prentice-Hall, Englewood Cliffs, 1984.

[21] Jang, R.; Sun, C.; Mizutani, E. Neuro-fuzzy and soft computation. Prentice Hall, New Jersey, 1997.

[22] Nazari-Shirkouhi, S.; Keramati, A.; Rezaie, K. Improvement of customers' satisfaction with new product design using an adaptive neuro-fuzzy inference systems approach. // Neural Computing and Applications. 23, 1(2013), pp. 333-343. https://doi.org/10.1007/s00521-013-1431-x

\section{Authors' addresses}

Amir Masoud Rahimi, Assistant Professor Civil Engineering Department,

Engineering Faculty, University of Zanjan, 45371-38791 Zanjan, Iran amrahimi@znu.ac.ir 